\title{
Comparison of Angiotensin-Converting Enzyme Inhibitor (ACEI) and Angiotensin Receptor Blocker (ARB) for Heart Failure Treatment in Congenital Heart Diseases with Left-to-Right Shunt
}

\author{
Alit Utamayasa $^{1, *}$, Mahrus Ahmad Rahman ${ }^{1}$, Teddy Ontoseno ${ }^{1}$, Budiono $^{2}$ \\ ${ }^{1}$ Departement of Child Health, Dr. Soetomo General Hospital, Faculty of Medicine, Universitas Airlangga, Jl. Mayjen Prof. Dr. Moestopo No. 6-8, \\ Surabaya, Indonesia \\ ${ }^{2}$ Departement of Public Health, Faculty of Medicine, Universitas Airlangga, Jl. Mayjen Prof. Dr. Moestopo no 47, Surabaya, Indonesia \\ *Corresponding author. E-mail: alit_tusari@yahoo.com
}

Received date: Oct 9, 2019; Revised date: Dec 6, 2019; Accepted date: Jan 3, 2020

\section{Abstract}

$\mathrm{B}$

ACKGROUND: The angiotensin-converting enzyme inhibitors (ACEIs) have become the forefront of heart failure treatment for more than a decade. Currently, angiotensin receptor blockers (ARBs) are thought to have similar effectiveness. This study aimed to compare the impact of captopril, one of ACEI, and valsartan, one of $\mathrm{ARB}$, on clinical presentation and echocardiographic, electrocardiographic, and chest x-ray improvement in patients with left-to-right shunt congenital heart diseases.

METHODS: This study used a double-blind randomized controlled trial of captopril and valsatran to children with left-to-right shunt congenital heart diseases who suffer from heart failure in the Dr. Soetomo General Hospital, Surabaya, Indonesia. Pediatric heart failure scores, echocardiography, electrocardiography (ECG), and chest photographs were examined at the beginning of the study and after 30 days of treatment.

\section{Introduction}

Congenital heart disease (CHD) is a disease that leads to heart structure and/or circulation function abnormalities that can be observed immediately after birth or later in life. Most of the cases are complex and require adequate treatment as early as possible.(1) The incidence of CHD in Indonesia is quite common. Nevertheless, proper facilities and infrastructure, including diagnostic, therapeutic,
RESULTS: A decrease in pediatric heart failure scores were showed after the administration of ACEI (7.06 \pm 2.04 vs. $4.75 \pm 2.43 ; p<0.0001 ; 95 \%$ CI: -2.98 - 1.65); ARB (6.81 \pm 2.25 vs. $3.94 \pm 1.98 ; p<0.0001 ; 95 \%$ CI: -3.76 to 1.98). The echocardiography examination, an increase in left ventricular end-diastolic volume (LVEDV), left ventricular ejection fraction (LVEF), \% fractional shortening (FS), and left ventricular (LV) dimension occurred after the administration of ACEI and ARB. The values also didn't significantly differrent between the two groups. The ECG evaluation showed a decrease in heart rate frequency after the administration of ACEI $(117.75 \pm 14.67 v s .109 .63 \pm 17.59$; $p=0.039 ; 95 \%$ CI: -15.78 to -0.46$)$ and ARB $(117.10 \pm 21.86$ vs. $108.6 \pm 20.66$; $p=0.006$; $95 \%$ CI: -14.17 to -2.83 ).

CONCLUSION: ARB showed better outcome in clinical condition, echocardiography, ECG, and chest radiographs.

KEYWORDS: captopril, valsartan, heart failure, congenital heart disease, left to right shunt

Indones Biomed J. 2020; 12(1): 62-8 and operative. for CHD treatment are still inadequate in Indonesia.(2)

CHD prevalence is estimated to be 6 to 10 per 1.000 live births, with an average of 8 out of 1.000 live births. Approximately one-third of them will show symptoms that vary from mild to severe, which may emerge in the first weeks of life.(3) If these symptoms are not detected earlier and not treated properly, $50 \%$ of deaths will occur in the first month of life. One of the most common complications that often occur in CHD is heart failure. Heart failure is the 
heart's inability as a blood pump to adequately meet the body's metabolic needs. This condition might be caused by primary heart muscle disorders or excessive cardiac burden or a combination of both.(1)

The current heart failure therapy for CHD is still unsatisfactory. Many trials in novel drugs have been conducted to treat heart failure. Management of heart failure in children is generally based on clinical experience and application of findings in trials involving adults, supported by limited literature and research in the pediatric population. Nevertheless, the clinical outcomes in children using drugs that have been proven to be beneficial in adults result in equally beneficial outcomes.(4) Angiotensin-converting enzyme inhibitors (ACEIs) have become the forefront of heart failure treatment for more than a decade. The most commonly used ACEIs are captopril and enalapril. Currently, angiotensin receptor blockers (ARBs) are thought to have similar effectiveness as ACEIs in treating hypertension, congestive heart failure, and chronic kidney disease.(5) Most of ARB research in heart failure was conducted in adults.(6) There is no similar study that is conducted in children with left-to-right shunt CHD who suffer from heart failure in Indonesia.

The aim of this study is to compare the clinical, echocardiographic, electrocardiographic, and chest radiograph changes before and after captopril administration and before and after valsartan administration on children with left-to-right CHD who have heart failure.

\section{Methods}

\section{Study Design}

The study was approved by the ethics commission of Dr. Soetomo General Hospital, Surabaya, Indonesia (No. 38/ Panke.KKE/02/II/2010). This study used randomized controlled trial (RCT) design in a double-blind study. The population of this study included the inpatients and outpatients of the Pediatric Cardiology Division of the Pediatric Department of Dr. Soetomo General Hospital, Surabaya, with left-to-right shunt CHD (ventricular septum defect (VSD), atrial septum defect (ASD), patent ductus arteriosus (PDA)) who met the criteria of heart failure using pediatric heart failure score.

\section{Pediatric Heart Failure Scoring}

Pediatric heart failure score consist of diaphoresis, tachipnea, breathing, respiratory rate, heart rate, and liver edge with criteria : No congestive heart failure (CHF): 0-2 points; Mild CHF: 3-6 points; Moderate CHF: 7-9 points; Severe CHF: 10-12 points.(7) The inclusion criteria in this study were children aged 1 to 16 years old who met the criteria of heart failure according to the pediatric heart failure scores with $>2$ score. The exclusion criteria were patients with surgery planned within one month, an impaired kidney function (GFR $<90 \mathrm{~mL} /$ minute $/ 1.73 \mathrm{~m}^{2}$ ), a serum potassium level $>5.5 \mathrm{mEq} / \mathrm{L}$. and a history of preceding heart failure therapy (captopril, furosemide, digitalis). The subjects were randomly selected and then sorted into two groups: valsartan and captopril, with a minimal sample of 16 children in each group.

\section{Clinical Examinations}

Each research subject was examined for echocardiography, electrocardiography (ECG), and chest radiograph. Echocardiography was performed with digital color ultrasonography developed by GE Medical System to identify left ventricular end-diastolic volume (LVEDV), left ventricular ejection fraction (LVEF), \% fractional shortening (FS), and left ventricular (LV) dimension by a consultant pediatric cardiologist. LVEDV is the final volume of left ventricular diastolic that is calculated based on the size of left ventricular internal diameter at end diastole (LVIDd), with a normal value $<5.6 \mathrm{~cm}$.(8) LVEF is the left ventricular ejection fraction that indicates heart pump function and is measured by the modified Simpson method ([end-diastolic volume (EDV) - end-systolic volume (ESV)] / $\mathrm{EDV} \times 100 \%$ ) with normal values between $56 \%$ and $78 \%$. (9) $\mathrm{LV}$ dimension is the distance between the two sides in the endocardium slightly below the bicuspid valve with a normal value based on body weight (lb). The $\% \mathrm{FS}=[$ left ventricular diastolic dimension (LVDD) - left ventricular systolic dimension (LVSD)]/(LVDD) refers to the percent changes in the left ventricular diameter that occurs during systole or shortening of the fraction as an indicator of the efficiency of the left ventricular pump with normal values ranging from $28 \%$ to $44 \%$.(8)

An ECG was performed with the patient lying in a relaxed state, using a cardiofax ECG device that was interpreted by a consultant pediatric cardiologist. From the chest radiograph, a chest $\mathrm{x}$-ray/CTR: cardiothoracic ratio (CTR) measurement was made using a ruler.

The sorting and distribution of drugs were carried out by the pharmaceutical department in a blind manner, and the drugs were given three times a day after meals for four weeks. Group 1 was given captopril at a dose of $0.3 \mathrm{mg} /$ 
$\mathrm{kg}$ body weight (BW) three times daily. Group 2 was given valsartan with a dose of $1.3 \mathrm{mg} / \mathrm{kg} \mathrm{BW}$ once a day in the morning after breakfast, and two other drugs in powder form containing placebo were given during the day and night. The drugs were given orally by doctors or paramedics for inpatients and with the help of their parents for the outpatients. To monitor the patients' compliance in taking the medicine, a checklist of drug administration was used and filled by the patients' parents or the patients themselves. If the drug was not taken, then the reason must be mentioned. All patients also received heart failure therapy, including diuretics (spironolactone) at a dose of $1 \mathrm{mg} / \mathrm{kg}$ once a day. After 30 days of drug administration, an evaluation of pediatric heart failure scores, ECG, echocardiography, chest radiograph, and adverse reactions was conducted.

\section{Statistical Analysis}

The collected data were analyzed using paired t-test to compare pre and post data, and Mann-Whitney test to compare valsartan $v s$. captopril, with significance level $p<0.05$. The data analysis was done using SPSS (IBM, New York, USA).

\section{Results}

During four months, from July to October 2010, 32 children were included as subjects and randomly divided into two groups, the captopril gruop and valsartan group. Each group consisted of 16 children, and their characteristics can be found in Table 1.

In this study, there was a decrease in pediatric heart failure scores after the administration of captopril (7.06 \pm 2.04 vs. $4.75 \pm 2.43 ; p<0.0001 ; 95 \%$ CI: -2.98 to 1.65) (Table 2). There was also a decrease in pediatric heart failure scores after the administration of valsartan (6.81 \pm 2.25 vs. $3.94 \pm 1.98 ; p<0.0001 ; 95 \% \mathrm{CI}:-3.76$ to 1.98$)$ (Table 3).

There was no differences in LVEDV, LVEF, \% FS, and $\mathrm{LV}$ dimension after the administration of captopril and valsartan $(p>0.05)$. The ECG evaluation showed a decrease in heart rate frequency after the administration of captopril and valsartan $(p<0.05)$ (Table 2 and Table 3$)$.

There were a no differences in pediatric heart failure scores, echocardiography, ECG, and CTR between captopril and valsartan group $(p>0.05)$ (Table 4.).

Table 1. Subjects' characteristics before the drug administration.

\begin{tabular}{lccc}
\hline \multicolumn{1}{c}{ Characteristics } & $\begin{array}{c}\text { Group 1 } \\
\text { (Captopril) }\end{array}$ & $\begin{array}{c}\text { Group 2 } \\
\text { (Valsartan) }\end{array}$ & p-value \\
\hline Age (months), Mean \pm SD & $73.4 \pm 55.8$ & $55.3 \pm 29.6$ & 0.263 \\
\hline Weight (kg), Mean \pm SD & $17.41 \pm 11.4$ & $14.9 \pm 7.8$ & 0.462 \\
\hline Sex, $\mathrm{n}$ & 6 & 6 & 1.000 \\
$\quad$ Male & 10 & 10 & \\
$\quad$ Female & & & \\
\hline Nutritional status, $\mathrm{n}(\%)$ & $1(6.3)$ & 0 & 0.966 \\
Over nourished & $4(25)$ & $6(37.5)$ & \\
Normal & $10(62.5)$ & $8(50.0)$ & \\
Malnourished & $1(6.3)$ & $2(12.5)$ & \\
$\quad$ Severely malnourished & & & \\
\hline Left-to-right shunt defect, $\mathrm{n}(\%)$ & $7(43.8)$ & $6(37.5)$ & \\
VSD & $5(31.2)$ & $3(18.7)$ & \\
ASD & $4(25.0)$ & $7(43.8)$ & \\
PDA & $36.8 \pm 0.2$ & $36.9 \pm 0.7$ & 0.511 \\
\hline Temperature (Celsius), Mean \pm SD & & & \\
\hline
\end{tabular}

SD: standar deviation; VSD: ventricular septum defect; ASD: atrial septum defect; PDA: patent ductus arteriosus. 
Table 2. Changes of clinical manifestation, echocardiography, ECG, and CTR in the captopril group.

\begin{tabular}{|c|c|c|c|c|}
\hline \multirow[b]{2}{*}{ Variables } & \multicolumn{2}{|c|}{ Group 1 (Captopril) } & \multirow[b]{2}{*}{$p$-value } & \multirow[b]{2}{*}{ CI 95\% } \\
\hline & $\begin{array}{c}\text { Pre } \\
(\text { Mean } \pm \text { SD })\end{array}$ & $\begin{array}{c}\text { Post } \\
(\text { Mean } \pm \text { SD })\end{array}$ & & \\
\hline Pediatric heart failure score & $7.06 \pm 2.04$ & $4.75 \pm 2.43$ & 0.000 & $-2.98-(-1.65)$ \\
\hline \multicolumn{5}{|l|}{ Echocardiography } \\
\hline $\operatorname{LVEDV}(\mathrm{g} / \mathrm{mL})$ & $44.58 \pm 20.05$ & $46.12 \pm 23.63$ & 0.689 & $-6.48-9.56$ \\
\hline LVEF (\%) & $74.54 \pm 3.84$ & $75.55 \pm 4.66$ & 0.423 & $-1.60-3.62$ \\
\hline FS $(\%)$ & $41.31 \pm 2.80$ & $42.21 \pm 5.17$ & 0.562 & $-2.35-4.17$ \\
\hline LV dimension $\left(\mathrm{g} / \mathrm{m}^{2}\right)$ & $3.29 \pm 0.58$ & $3.30 \pm 0.71$ & 0.961 & $-0.23-0.24$ \\
\hline \multicolumn{5}{|l|}{ ECG } \\
\hline Heart rate $(\mathrm{x} / \mathrm{min})$ & $117.75 \pm 14.67$ & $109.63 \pm 17.59$ & 0.039 & $-15.78-(-0.46)$ \\
\hline $\mathrm{R}$ amplitude in V1 lead (mV) & $7.06 \pm 6.69$ & $7.13 \pm 5.16$ & 0.962 & $-2.73-2.83$ \\
\hline $\mathrm{R}$ amplitude in V6 lead (mV) & $15.50 \pm 6.02$ & $13.63 \pm 7.66$ & 0.373 & $-6.23-2.48$ \\
\hline $\mathrm{S}$ amplitude in V1 lead (mV) & $6.38 \pm 5.12$ & $6.56 \pm 6.14$ & 0.885 & $-2.52-2.89$ \\
\hline S amplitude in V6 lead (mV) & $5.03 \pm 7.15$ & $3.59 \pm 4.88$ & 0.095 & $-3.16-0.28$ \\
\hline CTR $(\%)$ & $60.92 \pm 5.64$ & $59.61 \pm 5.16$ & 0.062 & $-2.70-0.07$ \\
\hline
\end{tabular}

SD: standar deviation; CI: confidence interval; LVEDV: left ventricular end-diastolic volume; LVEF: left ventricular ejection fraction; FS: fractional shortening; LV: left ventricular; ECG: electrocardiography; CTR: cardiothoracic ratio.

\section{Discussion}

In left-to-right shunt CHD with medium to large defect size, a volume overload occurs. The body will compensate as an adaptive response to a decrease of heart function that is marked by various adaptive responses in the form of myocardial dilatation and hypertrophy; peripheral vascular vasoconstriction and activation of the renin-angiotensinaldosterone system.(10) The effects of angiotensin II (A II) mediated by angiotensin II type 1 (AT1) receptors include vasoconstriction, salt retention, and growth changes in

Table 3. Changes of clinical manifestation, echocardiography, ECG, and CTR in the valsatran group.

\begin{tabular}{|c|c|c|c|c|}
\hline \multirow[b]{2}{*}{ Variables } & \multicolumn{2}{|c|}{ Group 2 (Valsartan) } & \multirow[b]{2}{*}{$p$-value } & \multirow[b]{2}{*}{ CI 95\% } \\
\hline & $\begin{array}{c}\text { Pre } \\
(M e a n \pm S D)\end{array}$ & $\begin{array}{c}\text { Post } \\
(\text { Mean } \pm \text { SD })\end{array}$ & & \\
\hline Pediatric heart failure score & $6.81 \pm 2.25$ & $3.94 \pm 1.98$ & 0.000 & $-3.76-(-1.98)$ \\
\hline \multicolumn{5}{|l|}{ Echocardiography } \\
\hline LVEDV (g/mL) & $58.74 \pm 29.77$ & $61.32 \pm 35.11$ & 0.721 & $-12.51-17.67$ \\
\hline LVEF (\%) & $74.26 \pm 3.86$ & $73.28 \pm 4.10$ & 0.494 & $-3.97-2.00$ \\
\hline FS $(\%)$ & $41.53 \pm 4.29$ & $41.11 \pm 3.48$ & 0.761 & $-3.24-2.42$ \\
\hline LV dimension $(\mathrm{g} / \mathrm{m} 2)$ & $3.64 \pm 0.72$ & $3.65 \pm 0.78$ & 0.919 & $-0.28-0.31$ \\
\hline \multicolumn{5}{|l|}{$\overline{\mathrm{ECG}}$} \\
\hline Heart rate $(\mathrm{x} / \mathrm{min})$ & $117.10 \pm 21.86$ & $108.60 \pm 20.66$ & 0.006 & $-14.17-(-2.83)$ \\
\hline $\mathrm{R}$ amplitude in V1 lead (mV) & $9.13 \pm 4.96$ & $7.69 \pm 2.91$ & 0.169 & $-3.56-0.68$ \\
\hline $\mathrm{R}$ amplitude in V6 lead (mV) & $16.60 \pm 6.62$ & $14.38 \pm 5.87$ & 0.125 & $-5.19-0.69$ \\
\hline $\mathrm{S}$ amplitude in V1 lead (mV) & $10.06 \pm 6.78$ & $7.31 \pm 5.99$ & 0.009 & $-4.69-(-0.81)$ \\
\hline $\mathrm{S}$ amplitude in V6 lead (mV) & $3.81 \pm 3.06$ & $3.53 \pm 2.70$ & 0.660 & $-1.61-1.05$ \\
\hline CTR $(\%)$ & $59.74 \pm 4.72$ & $57.19 \pm 5.14$ & 0.000 & $-3.87-1.23$ \\
\hline
\end{tabular}

SD: standar deviation; CI: confidence interval; LVEDV: left ventricular end-diastolic volume; LVEF: left ventricular ejection fraction; FS: fractional shortening; LV: left ventricular; ECG: electrocardiography; CTR: cardiothoracic ratio. 
Table 4. Changes of clinical manifestation, echocardiography, ECG, and CTR between the captopril and valsartan groups.

\begin{tabular}{lccc}
\multicolumn{1}{c}{ Variables } & $\begin{array}{c}\text { Group 1 (Captopril) } \\
\text { Mean } \pm \text { SD }\end{array}$ & $\begin{array}{c}\text { Group 2 (Valsartan) } \\
\text { Mean } \pm \text { SD }\end{array}$ & p-value \\
\hline Pediatric heart failure score & $-2.31 \pm 1.25$ & $-2.87 \pm 1.66$ & 0.289 \\
\hline Echocardiography & $1.53 \pm 15.06$ & $2.57 \pm 28.33$ & 0.898 \\
LVEDV $(\mathrm{g} / \mathrm{mL})$ & $1.01 \pm 4.90$ & $-0.98 \pm 5.61$ & 0.293 \\
LVEF (\%) & $0.91 \pm 6.12$ & $-0.41 \pm 5.31$ & 0.520 \\
FS (\%) & $0.01 \pm 0.45$ & $0.01 \pm 0.49$ & 0.961 \\
LV dimension (g/m $\left.\mathrm{m}^{2}\right)$ & & & \\
\hline ECG & $-8.12 \pm 14.37$ & $-8.50 \pm 10.63$ & 0.934 \\
Heart rate (x/min) & $0.062 \pm 5.20$ & $-1.43 \pm 3.98$ & 0.367 \\
R amplitude in V1 lead (mV) & $-1.87 \pm 8.17$ & $-2.25 \pm 5.53$ & 0.880 \\
R amplitude in V6 lead $(\mathrm{mV})$ & $0.187 \pm 5.08$ & $-2.75 \pm 3.64$ & 0.070 \\
S amplitude in V1 lead $(\mathrm{mV})$ & $-1.43 \pm 3.22$ & $-0.28 \pm 2.50$ & 0.267 \\
S amplitude in V6 lead (mV) & $-1.31 \pm 2.60$ & $-2.55 \pm 2.47$ & 0.178 \\
\hline CTR (\%) &
\end{tabular}

SD: standar deviation; LVEDV: left ventricular end-diastolic volume; LVEF: left ventricular ejection fraction; FS: fractional shortening; LV: left ventricular; ECG: electrocardiography; CTR: cardiothoracic ratio.

myocytes and cause heart remodelling.(11) Measurement and monitoring of left ventricular remodeling include the size and shape of the heart that can be assessed from chest radiographs through CTR size, from ECG through left ventricular hypertrophy finding, from echocardiography through measured LV dimension. LVEDV, FS, and ejection fraction.(12)

Various studies have been conducted to compare the use of ARB with ACEI. These studies were mostly conducted in adult patients and rarely in children. Losartan Heart Failure Survival Study, which was conducted in 200, recommends the use of ARB as an alternative therapy in patients who cannot tolerate the use of ACEI.(13)

Previous study reported that the addition of valsartan in heart failure patients who received standard therapy for an average of 23 months significantly improved the New York Heart Association (NYHA) functional class, left ventricular remodeling, and symptoms and signs of heart failure.(14) The administration of captopril and valsartan for six months in congestive heart failure patients improved heart failure symptoms as measured by increased NYHA class that was better than captopril administration alone.(15)

ARB blocks the effects of A II by inhibiting the AT1 receptor, and it is reported to affect LV hypertrophy regression and cardiac remodeling in hypertension and heart failure.(16) Valsartan works specifically by blocking the interaction of A II with AT1 receptors. An increase in A II is known to increase the stimulation of beneficial effects mediated by the AT2 receptor through vasodilation and antifibrinolytic mechanisms.(17)

In the present study, the results of the statistical analysis showed a significant change in pediatric heart failure scores $(p<0.0001)$ before and after captopril administration, as well as before and after valsartan administration, but the results were not statistically significant when compared with the two treatment groups (Table 4). These results were in accordance with Valsartan Heart Failure Trial (Val-HeFT) and Randomized Evaluation of Strategies for Left Ventricular Dysfunction (RESOLVD) studies that reported no significant differences in clinical scores after the administration of ACEI and ARB.(14) Nevertheless, in the present study, the average of pediatric heart failure score decrease appeared to be greater in the valsartan group than the captopril group. Therefore, the clinical improvement that occurred seemed to be better after valsartan administration. LVEDV reflects structural remodeling and diastolic filling. LVEF derives from LV volume. Although heart rate and FS both affect ejection fraction, they are further affected by LVEDV because the change in stroke volume tends to be smaller than the change in LVEDV. Decreased LVEF was associated with a poor prognosis for heart failure. The FS is derived from a linear measurement that quantitatively 
measures the function of ventricular contractility; therefore, it can be used as an indicator for the expansion of the structural remodeling of the ventricle.(14)

Long-term therapy for approximately three to four years with effective ACE inhibitors did not only reduce the volume of overloaded LV but also LV hypertrophy (LV mass) in the heart of children with left ventricular volume overload ( $p=0.0007)$.(18) Valsartan affected the morbidity and mortality of patients with heart failure $(p<0.001)$ by comparing ejection fraction, LV dimension, and neurohormonal plasma levels in a group that did not receive ACE therapy.(19)

In the present study, there was less increase of LVEDV and LV dimension after captopril administration compared with valsartan (Table 4). This result was not in accordance with a previous study, in their preliminary study of heart muscle fibrosis and LV stiffness in the dog model with heart failure, reported a significant reduction in LVEDV after captopril and valsartan administration for four weeks.(20)

In the present study, an increase in LVEF occurred after captopril administration even though the results of the statistical analysis were not significant compared with the valsartan group (Table 4 ). There was a greater $\%$ FS increase after captopril administration than the valsartan group, even though the results were not statistically significant.

The ECG components that were evaluated were heart rate frequency and $\mathrm{R}$ and $\mathrm{S}$ wave amplitude parameters. In this study, a statistically significant decrease in heart rate frequency was observed in both groups, but the average heart rate decrease in the valsartan group was greater than that in the captopril group.

A decrease in the $\mathrm{R}$ and $\mathrm{S}$ wave amplitudes at the V1 and V6 leads in the valsartan group was found, with a mean decrease in wave amplitude greater than that in the captopril group, although the statistical analysis did not show a significant difference except for the $\mathrm{S}$ wave amplitude parameters at the V1 leads. This result shows that in the valsartan group, there was a regression of LV hypertrophy that was marked by a decrease in the R wave amplitude at the V6 lead and the S wave amplitude at the V1 lead. Previous study compared the effects of losartan and valsartan on LV hypertrophy and LV function in patients with essential hypertension and concluded that a more significant LV hypertrophy regression occurred after valsartan administration for six months.(21)

Measurement and monitoring of left ventricular remodeling include the size and shape of the heart that can be assessed from a chest radiograph through CTR.
Cardiomegaly is assessed if CTR $>50 \%$. A significant decrease of CTR occurred in hypertensive patients with chronic peritoneal dialysis who received ARB compared with the control group for blood pressure variability and cardiovascular remodeling.(22) A decrease in CTR occurred after a combination of irbesartan with conventional therapy including ACEI in patients with heart failure.(23)

In the present study, a decrease of CTR was found after captopril and valsartan administration (Table 2 and Table 3). The statistical analysis results showed a significant decrease of CTR in the valsartan group (Table 3), and the mean reduction of CTR in the valsartan group was greater than that in the captopril group (Table 4).

A previous study reported that ARB is as effective as ACEI in reducing mortality and hospitalization due to heart failure.(24) In this study, evaluation after treatment concluded that valsartan might provide a better effect than captopril. In the valsartan group, the following were found: a decrease in pediatric heart failure score, a decrease in heart rate frequency, a decrease in the $\mathrm{R}$ wave amplitude at the V1 and V6 leads, a decrease in the S amplitude at the V1 lead, and a greater CTR decrease and fewer side effects than the captopril group. In this study, the relative risk (RR) was 0.857 , which means that heart failure occurred 0.8 times in the valsartan group relative to the captopril group. With RR $<1$, it can be concluded that valsartan decreases the risk of heart failure. Absolute risk reduction (ARR) $=0.125$, which means that the average absolute difference in the incidence of heart failure is 0.125 , with a positive ARR value indicating that valsartan is beneficial. Relative risk reduction $(R R R)=14.3 \%$, which shows that valsartan administration reduced heart failure by $14.3 \%$.

Valsartan with a half-life of six hours is given once a day, while captopril with a half-life of less than three hours is given two to three times a day. This condition shows that valsartan at a dose of $1.3 \mathrm{mg} / \mathrm{kgBW}$ once a day is safe enough to be given to a population of children with left-toright shunt who suffer from heart failure. Thus, valsartan is better than captopril.

Pharmacological failure associated with inadequate doses or the frequency of ACEI administration or the activity of non-ACE pathways remains unclear. Therefore, efforts to inhibit angiotensin more effectively by using valsartan appear to be more rational.(15)

The limitation of this stuty are limited subjects and short period observation. A research with a longer period is needed to observe the efficacy of valsartan in the process of cardiac remodeling. 


\section{Conclusion}

Valsartan administration resulted in improved clinical, echocardiographic, ECG, and chest radiographs and fewer side effects (coughing) compared with captopril. Valsartan can be used as one of the drug choices besides captopril for the treatment of heart failure in children with left-to-right shunt CHD.

\section{References}

1. Hinton RB, Ware SM. Heart failure in pediatric patients with congenital heart disease. Circ Res. 2017; 120: 978-94.

2. Murni IK, Musa NL. The need for specialized pediatric cardiac critical care training program in limited resource settings. Front Pediatr. 2018; 6: 59. doi: 10.3389/fped.2018.00059.

3. Yun SW. Congenital heart disease in the newborn requiring early intervention. Korean J Pediatr. 2011; 54: 183-91.

4. Begg S, Thompson A, Nash R, Tompson A, Peterson G. Cardiac Failure in Children. 17th Expert Committee on the Selection and Use of Essential Medicines. Geneva: WHO; 2009.

5. McMurray JJ, Östergren J, Swedberg K, Granger CB, Held P, Michelson EL, et al. Effects of candesartan in patients with chronic heart failure and reduced left-ventricular systolic function taking angiotensin-converting-enzyme inhibitors: the CHARM-Added trial. Lancet. 2003; 362: 767-71.

6. Flynn JT, Meyers KEC, Neto JP, de Paula Meneses R, Zurowska A, Bagga A, et al. Efficacy and safety of the angiotensin receptor blocker valsartan in children with hypertension aged 1 to 5 years. Hypertension. 2008; 52: 222-8.

7. Läer S, Mir TS, Behn F, Eiselt M, Scholz H, Venzke A, et al. Carvedilol therapy in pediatric patients with congestive heart failure: A study investigating clinical and pharmacokinetic parameters. Am Heart J. 2002; 143: 916-22.

8. Park MK. Pediatric Cardiology for Practitioners. 5th ed. Philadelphia: Mosby; 2008.

9. Shaffer EM. Quantitative echocardiography. In: Cruz LM, Cayre RO, editors. Echocardiographic Diagnosis of Congenital Heart Disease: An Embryologic and Anatomic Approach. Philadelphia: LippincottRaven; 1999. p.85-8.

10. Hartupee J, Mann DL. Neurohormonal activation in heart failure with reduced ejection fraction. Nat Rev Cardiol. 2017; 14: 30-8.

11. Bhakta S, Dunlap ME. Angiotensin-receptor blockers in heart failure: evidence from the CHARM trial. Clev Clin J Med. 2004; 71: $665-73$.
12. Konstam MA, Kramer DG, Patel AR, Maron MS, Udelson JE. Left ventricular remodeling in heart failure. JACC Cardiovasc Imaging. 2011; 4: 98-108.

13. Pitt B, Poole-Wilson PA, Segal R, Martinez FA, Dickstein K, Camm $\mathrm{AJ}$, et al. Effect of losartan compared with captopril on mortality in patients with symptomatic heart failure: randomised trial- the Losartan Heart Failure Survival Study ELITE II. Lancet. 2000; 3550: $1582-7$.

14. Cohn JN. Tognoni G. A randomized trial of the angiotensin-receptor blocker valsartan in chronic heart failure. N Engl J Med. 2001; 345: 1667-75.

15. Kasama S, Toyama T, Kumakura H, Takayama Y, Ichikawa S, Suzuki $\mathrm{T}$, et al. Addition of valsartan to an angiotensin-converting enzyme inhibitor improves cardiac sympathetic nerve activity and left ventricular function in patients with congestive heart failure. J Nucl Med. 2003; 44: 884-90.

16. Yasunari K, Maeda K, Nakamura M, Watanabe T, Yoshikawa J, Hirohashi K. Left ventricular hypertrophy and angiotensin II receptor blocking agents. Curr Med Chem Cardiovasc Hematol Agents. 2005; 3: 61-7.

17. Mehta PK, Griendling KK. Angiotensin II cell signaling: physiological and pathological effects in the cardiovascular system. Am J Physiol Cell Physiol. 2007; 292: C82-97.

18. Mori Y, Nakazawa M, Tomimatsu H, Momma K. Long-term effect of angiotensin-converting enzyme inhibitor in volume overloaded heart during growth: a controlled pilot study. J Am Coll Cardiol. 2000; 36: 270-5.

19. Maggioni AP, Anand I, Gottlieb SO, Latini R, Tognoni G, Cohn JN. Effects of valsartan on morbidity and mortality in patients with heart failure not receiving angiotensin-converting enzyme inhibitors. J Am Coll Cardiol. 2002; 40: 1414-21.

20. Funabiki K, Onishi K, Dohi K, Koji T, Imanaka-Yoshida K, Ito M, et al. Combined angiotensin receptor blocker and ACE inhibitor on myocardial fibrosis and left ventricular stiffness in dogs with heart failure. Am J Physiol Heart Circ Physiol. 2004; 287: H2487-92.

21. Picca M, Agozzino F, Pelosi G. Effects of losartan and valsartan on left ventricular hypertrophy and function in essential hypertension. Adv Ther. 2004; 21: 76-86.

22. Shigenaga A, Tamura K, Dejima T, Ozawa M, Wakui H, Masuda $\mathrm{S}$, et al. Effects of angiotensin II type 1 receptor blocker on blood pressure variability and cardiovascular remodeling in hypertensive patients on chronic peritoneal dialysis. Nephron Clin Pract. 2009; 112: $\mathrm{c} 31-40$.

23. Tonkon M, Awan N, Niazi I, Hanley P, Baruch L, Wolf RA, et al. A study of the efficacy and safety of irbesartan in combination with conventional therapy, including ACE inhibitors, in heart failure. Irbesartan Heart Failure Group. Int J Clin Pract. 2000; 54: 11-4, 16-8.

24. Lee VC, Rhew DC, Dylan M, Badamgarav E, Braunstein GD, Weingarten SR. Meta-analysis: angiotensin-receptor blockers in chronic heart failure and high-risk acute myocardial infarction. Ann Intern Med. 2004; 141: 693-704. 